This document is the accepted manuscript version of the following article:

Ritter, S., \& Seifert, H. P. (2008). Effect of corrosion potential on the corrosion

fatigue crack growth behaviour of low-alloy steels in high-temperature water. Journal

of Nuclear Materials, 375(1), 72-79. https://doi.org/10.1016/j.jnucmat.2007.10.010

This manuscript version is made available under the CC-BY-NC-ND 4.0

license http://creativecommons.org/licenses/by-nc-nd/4.0/

\title{
Effect of corrosion potential on the corrosion fatigue crack growth behaviour of low-alloy steels in high-temperature water
}

\author{
S. Ritter ${ }^{*}$, H.P. Seifert \\ Paul Scherrer Institute (PSI), Nuclear Energy and Safety Research Department, \\ Laboratory for Materials Behaviour, 5232 Villigen PSI, Switzerland \\ Tel.: +4156310 2983, Fax: +41563102199 \\ E-mail: stefan.ritter@psi.ch
}

\section{Abstract}

The low-frequency corrosion fatigue (CF) crack growth behaviour of different lowalloy reactor pressure vessel steels was characterized under simulated boiling water reactor conditions by cyclic fatigue tests with pre-cracked fracture mechanics specimens. The experiments were performed in the temperature range of 240 to $288^{\circ} \mathrm{C}$ with different loading parameters at different electrochemical corrosion potentials (ECPs). Modern high-temperature water loops, on-line crack growth monitoring (DCPD) and fractographical analysis by SEM were used to quantify the cracking response.

In this paper the effect of ECP on the CF crack growth behaviour is discussed and compared with the crack growth model of General Electric (GE). The ECP mainly affected the transition from fast ("high-sulphur") to slow ("low-sulphur") CF crack growth, which appeared as critical frequencies $v_{\text {crit }}=f(\Delta K, R, E C P)$ and $\Delta K$-thresholds $\Delta \mathrm{K}_{\mathrm{EAC}}=\mathrm{f}(\mathrm{v}, \mathrm{R}, \mathrm{ECP})$ in the cycle-based form and as a critical air fatigue crack growth rate $\mathrm{da} / \mathrm{dt}_{\mathrm{Air}, \text { crit }}$ in the time-domain form. The critical crack growth rates, frequencies, and $\Delta \mathrm{K}_{\mathrm{EAC}}$-thresholds were shifted to lower values with increasing ECP. The CF crack growth rates of all materials were conservatively covered by the "high-sulphur" CF line of the GE-model for all investigated temperatures and frequencies. Under most system conditions, the model seems to reasonably well predict the experimentally observed 
parameter trends. Only under highly oxidizing conditions (ECP $\left.\geq 0 \mathrm{mV}_{\mathrm{SHE}}\right)$ and slow strain rates/low loading frequencies the GE-model does not conservatively cover the experimentally gathered crack growth rate data. Based on the GE-model and the observed cracking behaviour a simple time-domain superposition-model could be used to develop improved reference CF crack growth curves for codes.

\section{Introduction}

The reactor pressure vessel (RPV) of boiling water reactors (BWRs) is the most critical pressure-boundary component as far as safety and plant life are concerned. Although most BWR RPV parts are usually protected by a stainless steel cladding with a high resistance against intergranular stress corrosion cracking (SCC), environmentally-assisted cracking (EAC) has to be considered as a potential RPV ageing mechanism, since in safety assessments an incipient crack, which penetrates the cladding has to be postulated. Furthermore, in several BWRs cladding was not applied or was removed at some RPV locations, e.g., at the highly stressed feedwater nozzle corner. Reliable quantitative EAC crack growth rate (CGR) data are therefore required for flaw tolerance evaluations and assessments of safety margins.

Although both, the accumulated operating experience of low-alloy steel primary pressure-boundary components and the experimental/theoretical laboratory background knowledge have basically confirmed the adequacy and conservative character of the ASME XI wet reference fatigue CGR curves under most BWR/normal water chemistry (NWC) operating circumstances [1-6], several unfavourable critical combinations of material, loading and environmental parameters, which can lead to accelerated CF with CGRs well above the ASME XI wet reference fatigue CGR curves [6], have been identified in research projects at Paul Scherrer Institute (PSI). In a recent study [7], the 
mitigation effect of BWR/hydrogen water chemistry (HWC) on SCC and CF crack growth was evaluated for these critical BWR parameter combinations. In the current paper some selected aspects of this study are discussed. After an introduction of the General Electric (GE) EAC crack growth model $[3,8]$, the effect of the electrochemical corrosion potential (ECP) on CF crack growth is summarized and compared to the predictions of the GE-model. Finally a simple time-domain superposition-model, which could serve as a basis for the development of new improved reference fatigue CGR curves, is briefly outlined.

\section{GE EAC crack growth model}

The GE EAC crack growth model for the low-alloy steel/high-temperature water system is based on the film rupture/anodic dissolution mechanism [3]. A linear superposition of fatigue and EAC crack growth is assumed for CF crack growth [8]. Characteristic cyclic CF crack growth prediction trends of the GE-model under BWR conditions are exemplarily shown in Figs. 1 (time-based form) and 2 (cycle-based form). Environmental acceleration of fatigue crack growth in high-purity hightemperature water is restricted to a certain air fatigue CGR and loading frequency range, which is dependent on the ECP and steel sulphur content. Above the upper limit, the cyclic crack growth $\Delta \mathrm{a} / \Delta \mathrm{N}$ is dominated by pure mechanical fatigue and does not depend on environment or loading frequency. Below the lower critical CGR/frequency "high-sulphur" crack-tip environment conditions cannot be maintained and the cyclic crack growth $\Delta \mathrm{a} / \Delta \mathrm{N}_{\mathrm{EAC}}$ drop down either to "low-sulphur" $\mathrm{CF}$ or air fatigue CGRs.

\section{Figure 1}

Figure 2 
In the GE-model, the CF crack growth through anodic dissolution is controlled by the crack-tip strain rate and the sulphur anion activity/pH in the crack-tip electrolyte, which govern the oxide film rupture frequency and the dissolution/repassivation behaviour after the film rupture event. The CF CGR increases with increasing crack-tip strain rate and sulphide content and saturates above a critical strain rate of $10^{-3} \mathrm{~s}^{-1}$ (continuous dissolution). Above a sulphide concentration of $0.02 \mathrm{ppm}$ ("low-sulphur threshold") in the crack-tip electrolyte, the formation of a new, protective oxide layer is increasingly delayed by increasing sulphide content, which thus leads to a larger increment of crack advance by anodic dissolution per oxide-rupture event. Above a sulphide content of 20 ppm ("high-sulphur threshold"), the sulphide effect on repassivation saturates and a further increase in sulphide concentration does no cause any additional delay of repassivation. Based on this relationship between sulphur anion activity and repassivation, derived experimentally under simulated crack-tip electrolyte conditions, a lower and upper limiting CF crack growth equation could be defined. The so-called "low-“ and "high-sulphur" CF lines represent a lower and upper bounding line for CF crack growth in low-alloy steel in high-temperature water. A critical high sulphur anion content has to be maintained in the crack-tip electrolyte to sustain fast "high-sulphur" CF CGRs (with strong environmental acceleration of fatigue crack growth), otherwise the CGRs quickly drop down to "low-sulphur" CGRs (with minor environmental acceleration) (Figs. 1 and 2). The transition from "high-" to "lowsulphur" CF CGRs is shifted to lower air fatigue CGRs (Fig. 1) and loading frequencies/ $\Delta \mathrm{K}$ (Fig. 2) exponentially with increasing ECP and linearly with increasing steel sulphur content and sulphate/sulphide concentration of the bulk environment.

A high ECP/dissolved oxygen (DO) content (sulphur anion enrichment/retention in the crack enclave by migration), a high sulphur anion concentration in the bulk 
environment, quasi-stagnant or low flow rate (no dilution by convection), a high steel sulphur content (dissolution of MnS inclusions), or a sufficiently high CGR/crack-tip strain rate/loading frequency ${ }^{*}$ (exposure of new, dissolvable $\mathrm{MnS}$ inclusions by the growing crack) favour the formation of a crack-tip environment rich in sulphur anions and therefore a high CF CGR. The crack-tip strain rate generally increases with increasing loading frequency/rate, load level, CGR, yield stress and susceptibility to dynamic strain ageing (DSA). [1, 3, 8-10]

\section{Materials and experimental procedure}

CF tests were performed under simulated BWR/NWC and HWC operating conditions. The applied testing procedure and used facilities are described in detail in $[9,11]$ and fully comply with the current state-of-the-art technology in laboratory testing of EAC processes.

\subsection{Materials}

Several types of low-alloy, nuclear grade RPV steels were investigated (Table 1) [9]. The investigated materials are characteristic for RPVs of Western light water reactors. Concerning the EAC behaviour, the steels mainly differ in their DSA susceptibility and sulphur content/MnS morphology.

All materials were quenched and tempered. Additionally, some materials were (post-weld) heat-treated or stress relieved. The RPV steels have a granular, bainitic (alloy A, C, D, E) or a mixed bainitic/ferritic-pearlitic structure (alloy B) with an average former austenitic grain size of 10 to $20 \mu \mathrm{m}$. The spatial distribution and morphology of the MnS inclusions is fairly homogeneous and similar in alloys A to D

\footnotetext{
* Although at high frequencies above $0.1 \mathrm{~Hz}$, in particular at low load ratios and in through-the-thickness cracks, the convective dilution of the crack-tip electrolyte by the relative displacement of the crack flanks between minimum and maximum stress portions during a fatigue cycle can counteract this type of enrichment of sulphides.
} 
covering the range from small, spherical to large (up to a few $100 \mu \mathrm{m}$ ), elongated inclusions. Alloy E revealed distinct banded sulphur segregation zones with large clusters of MnS inclusions.

\section{Table 1}

\subsection{Experimental procedure}

The CF tests were performed in 101 stainless steel autoclaves with integrated electromechanical loading systems, which were attached to sophisticated refreshing high-temperature water loops (Fig. 3). During the experiments all important data were recorded continuously. Usually, two air fatigue pre-cracked, $25 \mathrm{~mm}$ thick compact tension specimens $(1 \mathrm{~T} \mathrm{C}(\mathrm{T}))$ were simultaneously tested in a "daisy chain". The crack advance was continuously monitored using the reversed direct current potential drop (DCPD) method with a resolution limit of about 2 to $5 \mu \mathrm{m}$. The ECPs and redoxpotentials were measured with $\mathrm{Cu} / \mathrm{Cu}_{2} \mathrm{O} / \mathrm{ZrO}_{2}$-membrane or external $\mathrm{Ag} / \mathrm{AgCl} / 0.01 \mathrm{M}$ $\mathrm{KCl}$ reference electrodes. After the tests all specimens were broken open at liquid nitrogen temperature for fractographical analysis in the SEM.

\section{Figure 3}

Before the cyclic loading was applied, the specimens were pre-oxidized in the test environment at a small constant pre-load for one week. The subsequent cyclic loading in CF tests was performed under load control. Constant load amplitude loading with a positive saw tooth (slow loading, fast unloading) was applied. The rise time $\Delta t_{R}$, load ratio $\mathrm{R}$ and load level were varied over a very broad range. In most cases the $\mathrm{K}_{\mathrm{I} \text {, max }}$ values were below the ASTM E647 limit.

BWR conditions were mostly simulated with high-purity, hydrogenated (HWC) or oxygenated (NWC) water at a temperature of $288^{\circ} \mathrm{C}$. For HWC conditions, a dissolved 
hydrogen content of $150 \mathrm{ppb}$ was usually applied resulting in a redox-potential and an ECP of -530 and -550 to $-600 \mathrm{mV}_{\mathrm{SHE}}$, respectively. For NWC conditions, usually a DO content of 50, 400 or 8000 ppb was applied $\left(\mathrm{ECP}=-100,+50\right.$, or $\left.+150 \mathrm{mV}_{\mathrm{SHE}}\right)$. All tests were performed under low-flow conditions (4 to 5 autoclave exchanges per hour) with a local flow rate of some few $\mathrm{mm} / \mathrm{s}$ to generate conservative data with respect to most plant locations with turbulent high-flow conditions.

\section{Results and discussion}

In the following sections the effect of ECP/DO content on CF crack growth in lowalloy steel under BWR conditions is summarized and the results are compared to the predictions of the GE-model. Finally, a simple superposition-model, which could be used for the development of engineering reference fatigue crack growth curves in hightemperature water, is briefly introduced.

\subsection{Effect of ECP on the CF crack growth behaviour}

The effect of ECP on CF crack growth is exemplarily illustrated by Figs. 4 (cyclebased CGRs) and 5 (time-based CGRs) [12]. Depending on the loading conditions, the ECP/DO content either had a very pronounced or only a moderate effect on CF crack growth. Below a loading frequency of $10 \mathrm{~Hz}$, environmental acceleration of fatigue crack growth was observed for all ECPs/DO contents and the cycle-based CGRs $\Delta \mathrm{a} / \Delta \mathrm{N}_{\mathrm{EAC}}$ were increasing with decreasing loading frequency, following roughly the "high-sulphur" CF CGR line of the GE-model down to a frequency of $10^{-2} \mathrm{~Hz}$. In this frequency range, the same CF CGRs $\Delta \mathrm{a} / \Delta \mathrm{N}_{\mathrm{EAC}}$ were observed at a given frequency for low and high ECP/DO values. The slightly lower CF CGRs $\Delta \mathrm{a} / \Delta \mathrm{N}_{\mathrm{EAC}}$ at 400 to $8000 \mathrm{ppb}$ were related to the slightly lower loading level in these tests. Below a critical frequency $v_{\text {crit }}$ of $10^{-2}\left(<5\right.$ ppb DO) and $10^{-3} \mathrm{~Hz}(200 \mathrm{ppb}$ DO), the cyclic CGRs 
$\Delta \mathrm{a} / \Delta \mathrm{N}_{\mathrm{EAC}}$ dropped again down to "low-sulphur" CF CGRs slightly above the air fatigue CGRs, since "high-sulphur" crack-tip environment conditions could not be sustained anymore. On the other hand, in oxygenated high-temperature water with a DO content of 400 or $8000 \mathrm{ppb}$, fast CF crack growth with CGRs close to the "high-sulphur" CF CGRs could be sustained down to the lowest loading frequency tested $\left(10^{-5} \mathrm{~Hz}\right)$. Below $10^{-2} \mathrm{~Hz}$, significantly different cycle-based CGRs $\Delta \mathrm{a} / \Delta \mathrm{N}_{\mathrm{EAC}}$ were observed at the different ECP and DO values.

\section{Figure 4}

\section{Figure 5}

The ECP mainly affected the transition from high to low CF CGRs, which appeared as critical frequencies $v_{\text {crit }}=\mathrm{f}(\Delta \mathrm{K}, \mathrm{R}, \mathrm{ECP})$ and $\Delta \mathrm{K}$-thresholds $\Delta \mathrm{K}_{\mathrm{EAC}}=\mathrm{f}(\nu, \mathrm{R}, \mathrm{ECP})$ in the cycle-based form and as a critical air fatigue CGR da/dt $\mathrm{dir}_{\text {,crit }}=\mathrm{f}(\mathrm{ECP})$ in the timedomain form. The critical CGRs (Fig. 5) and frequencies (Fig. 4), as well as the $\Delta \mathrm{K}_{\mathrm{EAC}}-$ thresholds (Fig. 2) were shifted to lower values with increasing ECP (or DO content). In Fig. 6 some experimentally derived critical air fatigue CGRs da/dt $\mathrm{dir}_{\text {,crit }}$ for different ECPs are shown.

\section{Figure 6}

\subsection{Comparison to the GE-EAC crack growth model}

In general, a rather good correlation between the GE-model and the observed CF cracking trends was observed over a very wide range of system parameters. E.g., under highly oxidizing BWR/NWC and reducing HWC conditions, the low-frequency CF CGRs were close to the "high-sulphur" and "low-sulphur" CF line, respectively (Fig. 7). At ECPs $\leq-100 \mathrm{mV}_{\mathrm{SHE}}$, the model seems to reasonably well predict the experimentally observed parameter trends (Fig. 8) and critical air fatigue CGRs (Fig. 6). On the other 
hand, there is now some increasing experimental evidence that the GE-model is not conservative under highly oxidizing conditions ( $\mathrm{DO} \geq 0.4 \mathrm{ppm}, \mathrm{ECP} \geq 0 \mathrm{mV} \mathrm{SHE}_{\mathrm{SE}}$ ) and

very low loading frequencies $<10^{-4} \mathrm{~Hz}$. This is exemplarily shown in Fig. 8. The model therefore predicts too high critical frequencies $v_{\text {crit, }}$, air CGRs da/dt $\mathrm{dir}_{\text {,crit }}$, and $\Delta \mathrm{K}_{\mathrm{CF}^{-}}$ thresholds under these conditions. DSA, which is not considered in the GE-model in its present form, may be one possible reason for this discrepancy at low loading frequencies and high ECPs. In susceptible materials, DSA may affect the EAC behaviour at temperatures from 150 to $300{ }^{\circ} \mathrm{C}$ in particular at slow strain rates/low loading frequencies $<10^{-4} \mathrm{~s}^{-1} /<10^{-4} \mathrm{~Hz}$ (see [6]) by the strain localization and increase of yield stress/work hardening exponent $n\left(\sigma=\sigma_{0}+K \cdot \varepsilon^{n}\right)$. Within the DSA temperature-strain rate range, DSA may thus result in a higher crack-tip strain and strain rate than for identical loading conditions outside the DSA range, or than in a material which is not susceptible to DSA. DSA may therefore have a similar effect as an increase in loading frequency or $\Delta \mathrm{K}$.

\section{Figure 7}

\section{Figure 8}

\subsection{Superposition-model for CF crack growth in high-temperature water}

In the following paragraphs, a very simple superposition-model for the evolution of engineering reference fatigue crack growth curves in high-temperature water is outlined, which is based on the time-domain analysis and considers some of the basic ideas of the GE-model and some of the most dominant experimental parameter effects (ECP, frequency), but ignores material (steel sulphur content) aspects in the present form. In this model, the cycle-based CGR in high-temperature water $\Delta \mathrm{a} / \Delta \mathrm{N}_{\mathrm{EAC}}$ is just a simple linear superposition of the cycle-based CGR in air $\Delta \mathrm{a} / \Delta \mathrm{N}_{\text {Air }}$ by pure mechanical fatigue 
and of the corrosion-assisted CGR $\Delta \mathrm{a} / \Delta \mathrm{N}_{\mathrm{Env}}$. The first contribution is a purely cycliccontrolled process and independent of loading frequency. The second contribution only occurs during the rising load part of the fatigue cycle and is strongly dependent on crack-tip strain rate $\mathrm{d} \varepsilon / \mathrm{dt}_{\mathrm{CT}}$ ("high-sulphur" behaviour: da/dt $\mathrm{dnn} \alpha \cdot\left(\mathrm{d} \varepsilon / \mathrm{dt}_{\mathrm{CT}}\right)^{\mathrm{n}}$, "lowsulphur" behaviour: $\mathrm{da} / \mathrm{dt}_{\mathrm{Env}} \alpha \cdot\left(\mathrm{d} \varepsilon / \mathrm{dt}_{\mathrm{CT}}\right)$, saturation of $\mathrm{da} / \mathrm{dt}_{\mathrm{Env}}$ at high $\mathrm{d} \varepsilon / \mathrm{dt}_{\mathrm{CT}}$ in both cases ( $\rightarrow$ continuous dissolution)) and loading frequency. Under cyclic loading conditions it is assumed, that the crack-tip strain rate is proportional to the experimentally derived and known fatigue CGR in air (d $\left.\mathrm{d} / \mathrm{dt}_{\mathrm{CT}} \alpha \mathrm{da} / \mathrm{dt}_{\mathrm{Air}}\right)$ under otherwise identical loading conditions. For the onset of fast EAC ("critical sulphuranion concentration criteria", see [6]), the fatigue CGR in air da/dt $\mathrm{Air}_{\text {has }}$ to exceed a critical CGR da/dt $\mathrm{dir}_{\text {Air,crit, }}$ which is strongly dependent on the ECP. Based on these assumptions, the CF crack growth in high-temperature water can be described by the following equations, which are the basis of the so-called "time-domain analysis method" (Fig. 9):

$$
\begin{aligned}
& \mathrm{da} / \mathrm{dt}_{\mathrm{EAC}}=\mathrm{da} / \mathrm{dt}_{\mathrm{Env}}+\mathrm{da} / \mathrm{dt}_{\mathrm{Air}} \\
& \mathrm{da} / \mathrm{dt}_{\mathrm{Air}}=\mathrm{f}\left(\Delta \mathrm{t}_{\mathrm{R}}, \Delta \mathrm{K}, \mathrm{R}\right) \text {, e.g., ASME XI air CGR equation } \\
& \mathrm{da} / \mathrm{dt}_{\text {Env }} \text { : } \\
& -\mathrm{da} / \mathrm{dt}_{\mathrm{Air}}<\mathrm{da} / \mathrm{dt}_{\text {Air,crit }}=\mathrm{f}(\mathrm{ECP}): \quad \mathrm{da} / \mathrm{dt}_{\mathrm{Env}}=3 \cdot \mathrm{da}^{-\mathrm{dt}_{\mathrm{Air}}} \\
& -\mathrm{da} / \mathrm{dt}_{\text {Air,crit }}=\mathrm{f}(\mathrm{ECP}) \leq \mathrm{da} / \mathrm{dt}_{\text {Air }}<3.7 \cdot 10^{-8} \mathrm{~m} / \mathrm{s}: \quad \mathrm{da} / \mathrm{dt}_{\mathrm{Env}}=\mathrm{C} \cdot\left(\mathrm{da} / \mathrm{dt}_{\text {Air }}\right)^{\mathrm{m}} \\
& -\mathrm{da} / \mathrm{dt}_{\mathrm{Air}} \geq 3.7 \cdot 10^{-8} \mathrm{~m} / \mathrm{s}: \quad \mathrm{da} / \mathrm{dt}_{\mathrm{Env}}=2.3 \cdot 10^{-7} \mathrm{~m} / \mathrm{s}
\end{aligned}
$$

These equations can be easily transformed in a cycle-based form by multiplying them with the rise time $\Delta t_{R}$ or dividing them by the doubled loading frequency $2 \cdot v$. In contrast to the time-based form, the cycle-based form $\left(\Delta \mathrm{a} / \Delta \mathrm{N}_{\mathrm{EAC}}\right.$ vs. $\left.\Delta \mathrm{K}\right)$ splits into different curves for each $v$-R combination. The parameters $\mathrm{C}, \mathrm{m}$ and $\mathrm{da} / \mathrm{dt}_{\mathrm{Air}, \text { crit }}$ have to be determined by regression analysis of conservative experiments (e.g., by adequate 
materials (high sulphur content and high DSA susceptibility), decreasing frequency and high load ratio tests, $200-290^{\circ} \mathrm{C}$, etc.) for different important ECP regimes, (e.g., BWR/NWC, BWR/HWC and pressurized water reactor conditions). In contrast to $\mathrm{da} / \mathrm{dt}_{\mathrm{Air}, \text { crit, }} \mathrm{C}$ and $\mathrm{m}$ are not dependent on ECP (Figs. 2 and 5). Based on $\mathrm{da} / \mathrm{dt}_{\mathrm{Air}, \text { crit }}=\mathrm{f}(\mathrm{ECP})$, thresholds $\Delta \mathrm{K}_{\mathrm{EAC}}=\mathrm{f}(v, \mathrm{R}, \mathrm{ECP})$ and critical frequencies $v_{\text {crit }}=\mathrm{f}(\Delta \mathrm{K}, \mathrm{R}, \mathrm{ECP})$ for the onset of EAC can be derived. The CF crack growth behaviour of low-alloy steels in oxygenated high-temperature water can therefore be reasonably described by the proposed model and by one single curve in the time-based form for a given ECP value. Furthermore, it directly considers frequency and ECP effects and inherently defines "immunity conditions", where environmental effects on fatigue crack growth can be excluded or neglected (Fig. 9). In the time-base form, this superposition-model can be easily extended by an SCC crack growth part.

\section{Figure 9}

Such a time-domain analysis for a large data base of CF tests $[9,13]$ in oxygenated high-temperature water (simulated BWR/NWC operating conditions) is shown in

Fig. 10. The air fatigue CGRs da/ $\mathrm{dt}_{\text {Air }}$ have been calculated according to Eason $[15,16]$. Despite the wide range of parameters, all CF CGR data were lying in a relatively small scatter band of one half to one order of magnitude and within a factor of 5 of the calculated regression curve. The data indicates a critical CGR da/ $\mathrm{dt}_{\mathrm{Air}, \text { crit }}<10^{-13} \mathrm{~m} / \mathrm{s}$ under highly oxidizing BWR/NWC conditions $\left(+50 \leq \mathrm{ECP} \leq+200 \mathrm{mV}_{\mathrm{SHE}}\right)$.

\section{Figure 10}

A time-domain superposition analysis of a set of PSI data at different ECP regimes can be described by the following equations:

$$
\begin{aligned}
& \mathrm{da} / \mathrm{dt}_{\mathrm{EAC}}=\mathrm{da} / \mathrm{dt}_{\text {Env }}+\mathrm{da} / \mathrm{dt}_{\text {Air }} \\
& \mathrm{da} / \mathrm{dt}_{\text {Air }}=\mathrm{f}\left(\Delta \mathrm{K}, \mathrm{R}, \Delta \mathrm{t}_{\mathrm{R}}\right)=\left(7.87 \cdot 10^{-11} / \Delta \mathrm{t}_{\mathrm{R}}\right) \cdot(\Delta \mathrm{K} /(2.88-\mathrm{R}))^{3.07}
\end{aligned}
$$




$$
\begin{array}{ll}
\mathrm{da} / \mathrm{dt}_{\text {Air }}<\mathrm{da} / \mathrm{dt}_{\text {Air,crit }}=\mathrm{f}(\mathrm{ECP}): & \mathrm{da} / \mathrm{dt}_{\text {Env }}=3 \cdot \mathrm{da} / \mathrm{dt}_{\text {Air }} \\
\mathrm{da} / \mathrm{dt}_{\text {Air,crit }} \leq \mathrm{da} / \mathrm{dt}_{\text {Air }}<3.7 \cdot 10^{-8} \mathrm{~m} / \mathrm{s}: & \mathrm{da} / \mathrm{dt}_{\text {Env }}=6.6 \cdot 10^{-3} \cdot\left(\mathrm{da} / \mathrm{dt}_{\text {Air }}\right)^{0.6} \\
\mathrm{da} / \mathrm{dt}_{\text {Air }} \geq 3.7 \cdot 10^{-8} \mathrm{~m} / \mathrm{s}: & \mathrm{da} / \mathrm{dt}_{\text {Env }}=2.3 \cdot 10^{-7} \mathrm{~m} / \mathrm{s}
\end{array}
$$

(in $\mathrm{m} / \mathrm{s}, \mathrm{s}$ and $\mathrm{MPa} \cdot \mathrm{m}^{1 / 2}$ )

Critical air fatigue CGRs da/dt $\mathrm{dir}_{\text {,crit }}$ for high-sulphur steels and low-flow conditions for three different ECP regimes are summarizes here:

$$
\begin{array}{ll}
\text { ECP }=-500 \mathrm{mV}_{\mathrm{SHE}}: & \mathrm{da} / \mathrm{dt}_{\text {Air,crit }} \approx 7 \cdot 10^{-10} \mathrm{~m} / \mathrm{s} \\
\mathrm{ECP}=-100 \mathrm{mV}_{\mathrm{SHE}}: & \mathrm{da} / \mathrm{dt}_{\text {Air,crit }} \approx 8 \cdot 10^{-11} \mathrm{~m} / \mathrm{s} \\
\mathrm{ECP}=+200 \mathrm{mV}_{\mathrm{SHE}}: & \mathrm{da} / \mathrm{dt}_{\text {Air,crit }}<1 \cdot 10^{-13} \mathrm{~m} / \mathrm{s}
\end{array}
$$

In Fig. 11, predictions based on equations (6) to (10) are compared to experimental data [7]. A reasonably good correlation is observed for these testing conditions, which reveals the potential of this model for the prediction of CF CGR data of low-alloy steels and for the development of improved engineering reference fatigue crack growth curves in high-temperature water.

\section{Figure 11}

\section{Summary and conclusions}

The low-frequency $\left(\leq 10^{-2} \mathrm{~Hz}\right) \mathrm{CF}$ crack growth behaviour of different RPV steels was characterized under simulated BWR/NWC and HWC conditions by cyclic fatigue tests with pre-cracked fracture mechanics specimens. The effect of ECP on the crack growth behaviour was discussed and the test results were compared to the GE EAC crack growth model. Finally a superposition-model for the development of improved reference fatigue crack growth curves was presented. In the following paragraphs, the most important conclusions are summarized: 
Effect of ECP: The ECP mainly affected the transition from fast ("high-sulphur") to slow ("low-sulphur”) CF crack growth, which appeared as critical frequencies $v_{\text {crit }}=$ $\mathrm{f}(\Delta \mathrm{K}, \mathrm{R}, \mathrm{ECP})$ and $\Delta \mathrm{K}$-thresholds $\Delta \mathrm{K}_{\mathrm{EAC}}=\mathrm{f}(\nu, \mathrm{R}, \mathrm{ECP})$ in the cycle-based form and as critical air fatigue CGRs da/dt $\mathrm{dir}_{\text {,crit }}=\mathrm{f}(\mathrm{ECP})$ in the time-domain form. The critical CGRs, frequencies, and $\Delta \mathrm{K}_{\mathrm{EAC}}$-thresholds were shifted to lower values with increasing ECPs (or DO contents).

GE-model: The CF CGRs of all materials were conservatively covered by the "highsulphur" CF line of the GE-model for all investigated temperatures and frequencies. At most system conditions, the GE-model seems to reasonably well predict the experimentally observed parameter trends. Only under highly oxidizing conditions (DO $\geq 0.4 \mathrm{ppm}, \mathrm{ECP} \geq 0 \mathrm{mV}_{\mathrm{SHE}}$ ) and slow strain rates/low loading frequencies the GEmodel does not conservatively cover the experimentally gathered CGR data. DSA, which is not considered in the GE-model, could be the reason for this discrepancy at low loading frequencies and high ECPs.

Superposition-model: A simple time-domain superposition-model, which includes both ECP and loading frequency effects, gives an accurate and realistic description of the CF crack growth behaviour of low-alloy steels in high-temperature water over a wide range of system conditions. This model could reduce most of the undue conservatism and eliminate uncertainties of the existing codes and therefore serve as a basis for the development of improved reference fatigue crack growth curves.

\section{Acknowledgement}

This work has been performed within the RIKORR-I/II projects. The financial support for this work by the Swiss Federal Nuclear Safety Inspectorate (HSK) and the Swiss Federal Office of Energy (BFE) is gratefully acknowledged. Thanks are also 
expressed to U. Ineichen, B. Gerodetti, U. Tschanz and E. Groth (all PSI) for their experimental contribution to the projects.

\section{References}

[1] H.P. Seifert, S. Ritter, J. Hickling, Power Plant Chemistry 6 (2004) 111-123.

[2] Y.S. Garud et al., Corrosion fatigue of water-touched pressure retaining components in power plants, EPRI TR-106696, Final Report, November 1997.

[3] F.P. Ford, Environmentally assisted cracking of low-alloy steels, EPRI NP-7473L, Palo Alto, CA, USA, 1992.

[4] P. Scott, D. Tice, Nuclear Engineering and Design 119 (1990) 399-413.

[5] J. Hickling, D. Blind, Nuclear Engineering and Design 91 (1986) 305-330.

[6] H.P. Seifert, S. Ritter, Research and service experience with environmentallyassisted cracking in carbon and low-alloy steels in high-temperature water, SKIReport 2005:60, Stockholm, Sweden, 2005.

[7] H.P. Seifert, S. Ritter, U. Ineichen, B. Gerodetti, RIKORR-II: Risskorrosion in druckführenden ferritischen Komponenten des Primärkreislaufes von Siedewasserreaktoren, BFE Final Report, Villigen, Switzerland, 2006.

[8] F.P. Ford, P.L. Andresen, Corrosion fatigue of A533B/A508 pressure vessel steels in $288^{\circ} \mathrm{C}$ water, in: W. Cullen (Ed.), Proc. of the $3^{\text {rd }}$ Int. IAEA Specialist's Meeting on Sub-critical Crack Growth, Vol. 1, pp. 105-124, NUREG/CP-0112, Moscow, USSR, May 14-17, 1990.

[9] H.P. Seifert, S. Ritter, U. Ineichen, U. Tschanz, B. Gerodetti, Risskorrosion in druckführenden ferritischen Komponenten des Primärkreislaufes von Siedewasserreaktoren, PSI-Report 03-10, Villigen, Switzerland, 2003. 
[10] H.P. Seifert, Literature survey on the stress corrosion cracking of low-alloy steels in high-temperature water, PSI-Report 02-06, Villigen, Switzerland, 2002.

[11] S. Ritter, H.P. Seifert, Power Plant Chemistry 5 (2003) 17-29.

[12] S. Ritter, H.P. Seifert, Journal of Nuclear Materials 360 (2007) 170-176.

[13] H.P. Seifert, S. Ritter, Corrosion fatigue crack growth behaviour of low-alloy RPV and piping steels under BWR conditions, in: Proc. of the $3^{\text {rd }}$ International Conference on Fatigue of Reactor Components, NEA, Seville, Spain, October 3-6, 2004.

[14] P.L. Andresen, L.M. Young, Corrosion 51 (1995) 223-233.

[15] E. Eason et al., Nuclear Engineering and Design 184 (1998) 89-111.

[16] E. Eason et al., WRC Bulletin 404 (1995) 38-51. 


\section{List of abbreviations}

$\begin{array}{ll}\text { BWR } & \text { Boiling water reactor } \\ \text { C(T) } & \text { Compact tension (specimen) } \\ \text { CF } & \text { Corrosion fatigue } \\ \text { CGR } & \text { Crack growth rate } \\ \text { CT } & \text { Crack-tip } \\ \Delta \text { K } & \Delta \mathrm{K}=\mathrm{K}_{\mathrm{I}}^{\mathrm{max}}-\mathrm{K}_{\mathrm{I}}^{\text {min }: \text { Total stress intensity factor range }} \\ \text { DCPD } & \text { Direct current potential drop (method) } \\ \text { DO } & \text { Dissolved oxygen } \\ \text { DSA } & \text { Dynamic strain ageing } \\ \text { EAC } & \text { Environmentally-assisted cracking } \\ \text { ECP } & \text { Electrochemical corrosion potential } \\ \text { Env } & \text { Environment } \\ \text { GE } & \text { General Electric } \\ \text { HWC } & \text { Hydrogen water chemistry } \\ \boldsymbol{V} & \text { Loading frequency } \\ \text { NWC } & \text { Normal water chemistry } \\ \text { PSI } & \text { Paul Scherrer Institute, Villigen, Switzerland } \\ \text { R } & \text { Load ratio } \\ \text { RPV } & \text { Reactor pressure vessel } \\ \text { SCC } & \text { Stress corrosion cracking } \\ \text { SEM } & \text { Scanning electron microscope } \\ \text { SHE } & \text { Standard hydrogen electrode }\end{array}$


Table 1

Overview on investigated low-alloy RPV steels $(\mathrm{WQ}=$ water quenched, $\mathrm{FC}=$ furnace cooled, $\mathrm{AC}=$ air cooled, $\mathrm{SR}=$ stress relief heat-treatment, $\mathrm{DSA}=$ dynamic strain ageing: +++ : high, ++ : medium, + : low DSA susceptibility)

\begin{tabular}{|c|c|c|c|c|c|c|c|c|}
\hline Material & & $\begin{array}{c}\mathrm{S} \\
{[\mathrm{wt} . \%]}\end{array}$ & $\begin{array}{c}\mathrm{Al} \\
{[\mathrm{wt} \% \text { \%] }}\end{array}$ & $\begin{array}{l}\mathrm{N}_{\text {free }} \\
{[\mathrm{ppm}]}\end{array}$ & Heat treatment & $\begin{array}{l}\text { Micro- } \\
\text { structure }\end{array}$ & $\begin{array}{l}\mathrm{R}_{\mathrm{P}}{ }^{288^{\circ} \mathrm{C}} \\
{[\mathrm{MPa}]}\end{array}$ & DSA \\
\hline $\begin{array}{l}20 \mathrm{MnMoNi} 55 \\
(\equiv \mathrm{SA} 508 \mathrm{Cl} .3)\end{array}$ & A & 0.004 & 0.013 & 30 & $\begin{array}{l}910-920^{\circ} \mathrm{C} / 6 \mathrm{~h} / \mathrm{WQ} \\
640-650^{\circ} \mathrm{C} / 9.5 \mathrm{~h} / \mathrm{FC}\end{array}$ & Bainitic & 418 & +++ \\
\hline $\begin{array}{c}\text { SA } 508 \mathrm{Cl} .2 \\
(\equiv 22 \mathrm{NiMoCr} 37)\end{array}$ & B & 0.004 & 0.015 & 2 & $\begin{array}{l}900^{\circ} \mathrm{C} / 8 \mathrm{~h} / \mathrm{WQ} \\
600^{\circ} \mathrm{C} / 9 \mathrm{~h} / \mathrm{AC}\end{array}$ & $\begin{array}{l}\text { Bainitic/ } \\
\text { ferritic- } \\
\text { pearlitic }\end{array}$ & 396 & +++ \\
\hline $\begin{array}{c}\text { SA } 533 \text { B Cl.1 } \\
(\equiv 20 \text { MnMoNi } 5 \text { 5) }\end{array}$ & $\mathrm{C}$ & 0.018 & 0.030 & $<1$ & $\begin{array}{c}915^{\circ} \mathrm{C} / 12 \mathrm{~h} / \mathrm{AC} / 860^{\circ} \mathrm{C} / 12 \mathrm{~h} / \mathrm{WQ} \\
660^{\circ} \mathrm{C} / 12 \mathrm{~h} / \mathrm{FC} / 610^{\circ} \mathrm{C} / 40 \mathrm{~h} / \mathrm{FC} \\
550^{\circ} \mathrm{C} / 12 \mathrm{~h} / \mathrm{FC} / 550^{\circ} \mathrm{C} / 12 \mathrm{~h} / \mathrm{FC}\end{array}$ & Bainitic & 412 & ++ \\
\hline $\begin{array}{l}22 \mathrm{NiMoCr} 37 \\
(\equiv \mathrm{SA} 508 \mathrm{Cl} .2)\end{array}$ & $\mathrm{D}$ & 0.007 & 0.018 & 3 & $\begin{array}{c}890-900^{\circ} \mathrm{C} / 7 \mathrm{~h} / \mathrm{WQ} \\
640-650^{\circ} \mathrm{C} / 17 \mathrm{~h} / \mathrm{AC}+\mathrm{SR}\end{array}$ & Bainitic & 400 & + \\
\hline $\begin{array}{l}20 \mathrm{MnMoNi} 55 \\
(\equiv \mathrm{SA} 508 \mathrm{Cl} .3)\end{array}$ & $\mathrm{E}$ & $\begin{array}{c}0.015 \\
(0.003- \\
0.053)\end{array}$ & 0.029 & $?$ & $\begin{array}{c}900^{\circ} \mathrm{C} / 9 \mathrm{~h} / \mathrm{WQ} / 650^{\circ} \mathrm{C} / 34 \mathrm{~h} / \mathrm{AC} \\
660^{\circ} \mathrm{C} / 14 \mathrm{~h} / \mathrm{AC} / 550^{\circ} \mathrm{C} / 47 \mathrm{~h} \\
600^{\circ} \mathrm{C} / 8 \mathrm{~h} / \mathrm{AC}\end{array}$ & Bainitic & 439 & ++ \\
\hline
\end{tabular}




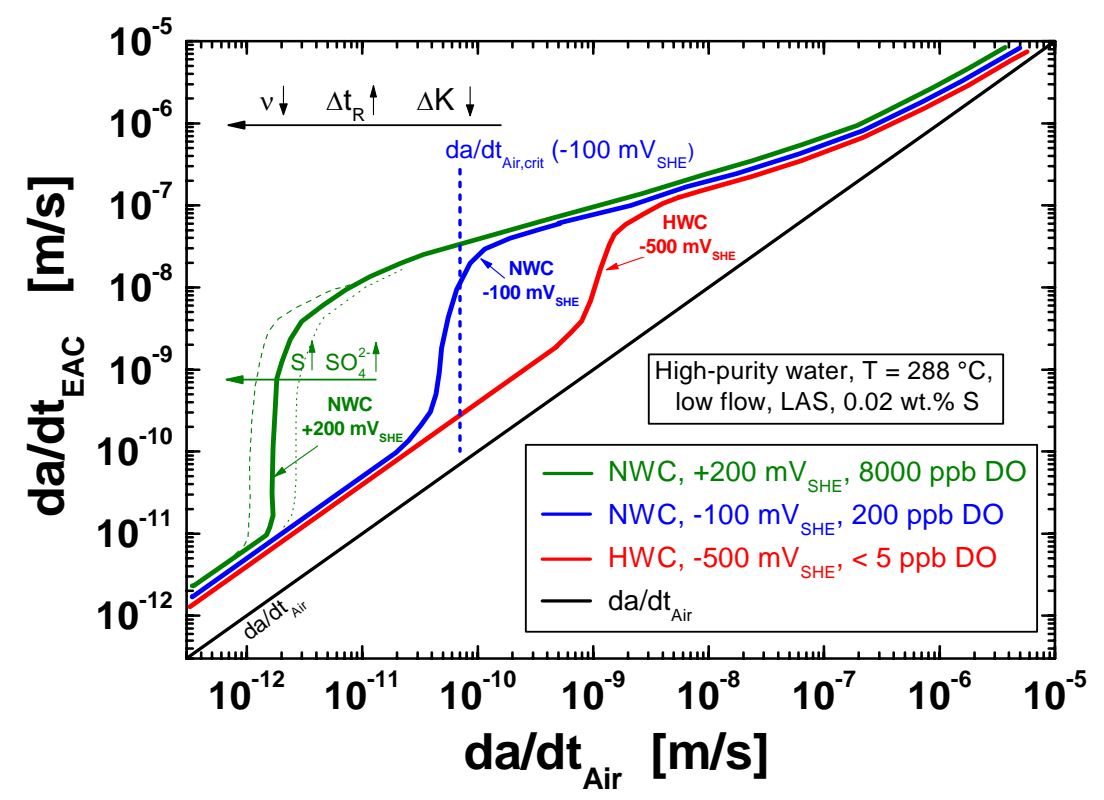

Fig. 1. Comparison of the time-based CF CGR da/dt $\mathrm{EAC}_{\mathrm{EC}}$ in oxygenated, high-purity high-temperature water at different ECP-levels according to the GE-model with the corresponding fatigue CGR in air $\mathrm{da} / \mathrm{dt}_{\mathrm{Air}}$ under otherwise identical loading and system conditions (= time-domain plot). 

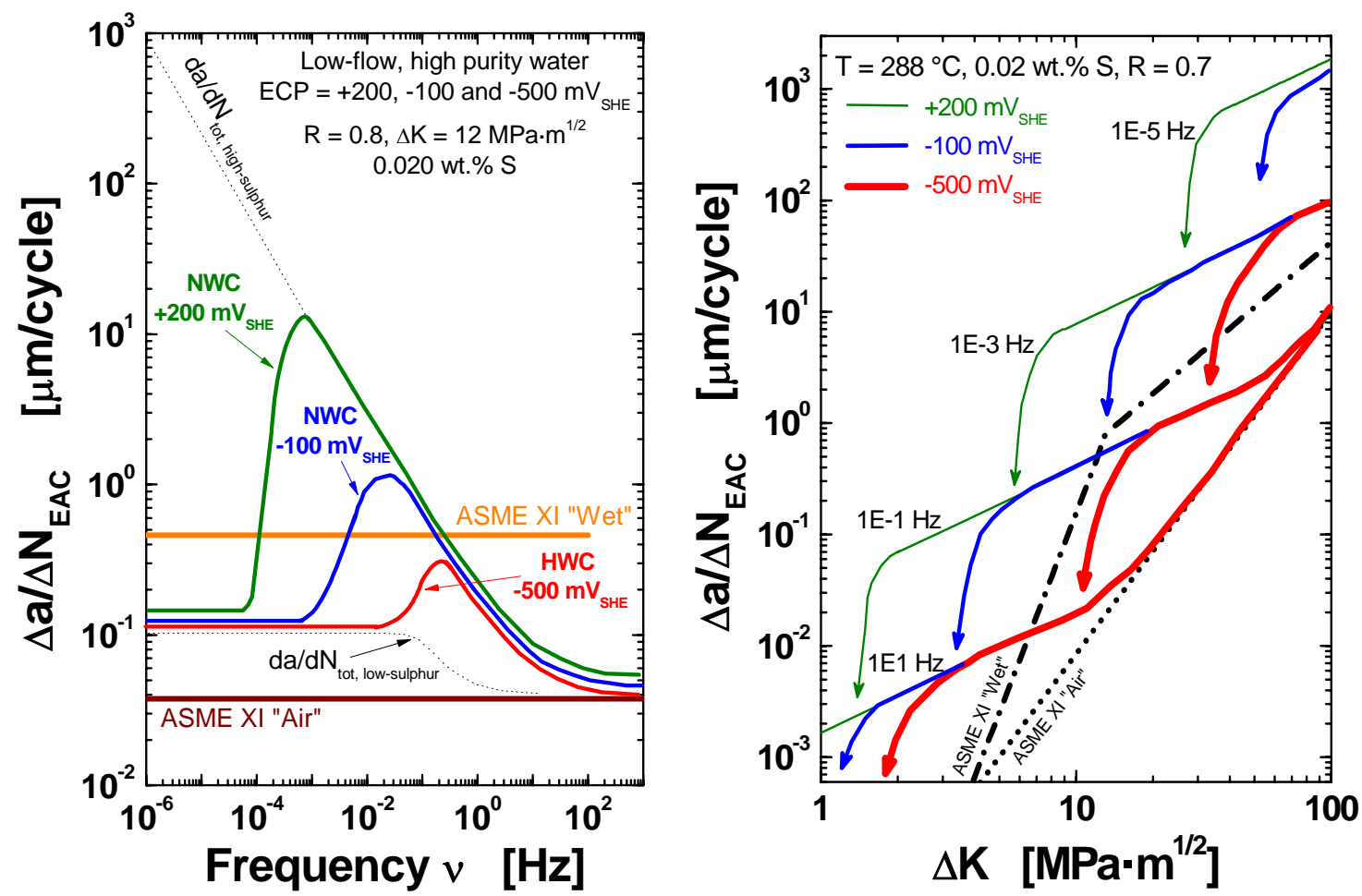

Fig. 2. Effect of loading frequency $v$ (left plot) and $\Delta \mathrm{K}$ (right plot) on the cycle-based CGR $\Delta \mathrm{a} / \Delta \mathrm{N}_{\mathrm{EAC}}$ in oxygenated, high-purity high-temperature water at three different ECP/DO-levels according to the GEmodel. Additionally, the model predictions are compared to the corresponding ASME XI reference fatigue CGR curves for the given loading conditions. 


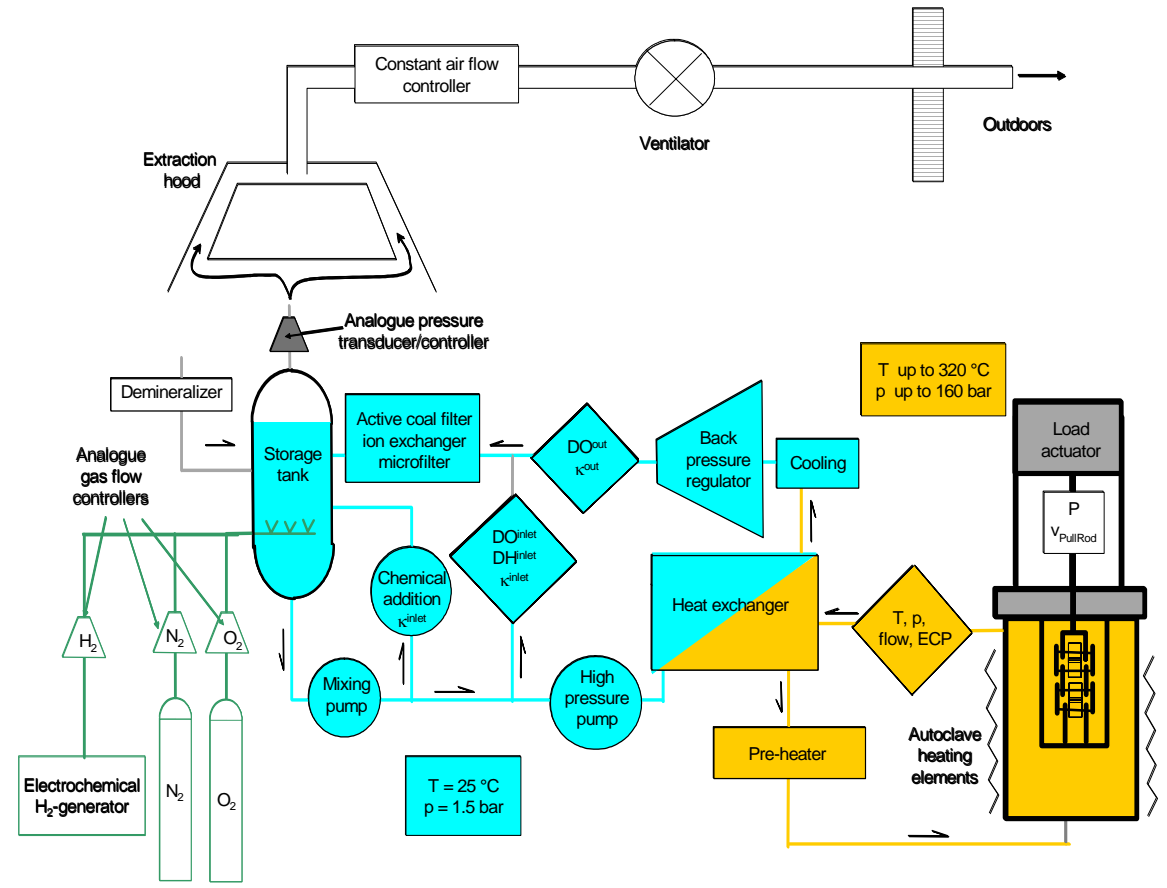

Fig. 3. High-temperature water loop with autoclave and electro-mechanical tensile machine. 


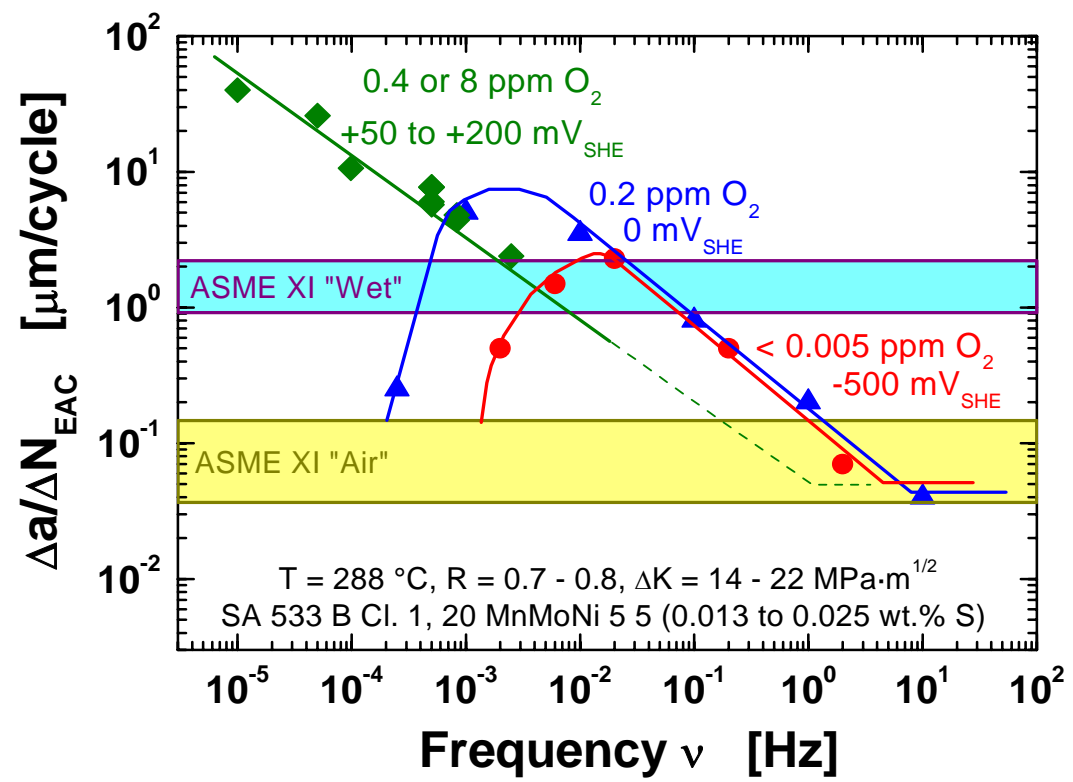

Fig. 4. Effect of ECP/DO content and loading frequency on the cycle-based CGRs $\Delta \mathrm{a} / \Delta \mathrm{N}_{\mathrm{EAC}}$ and comparison to the corresponding ASME XI reference fatigue CGRs for the specified loading conditions [13]. 


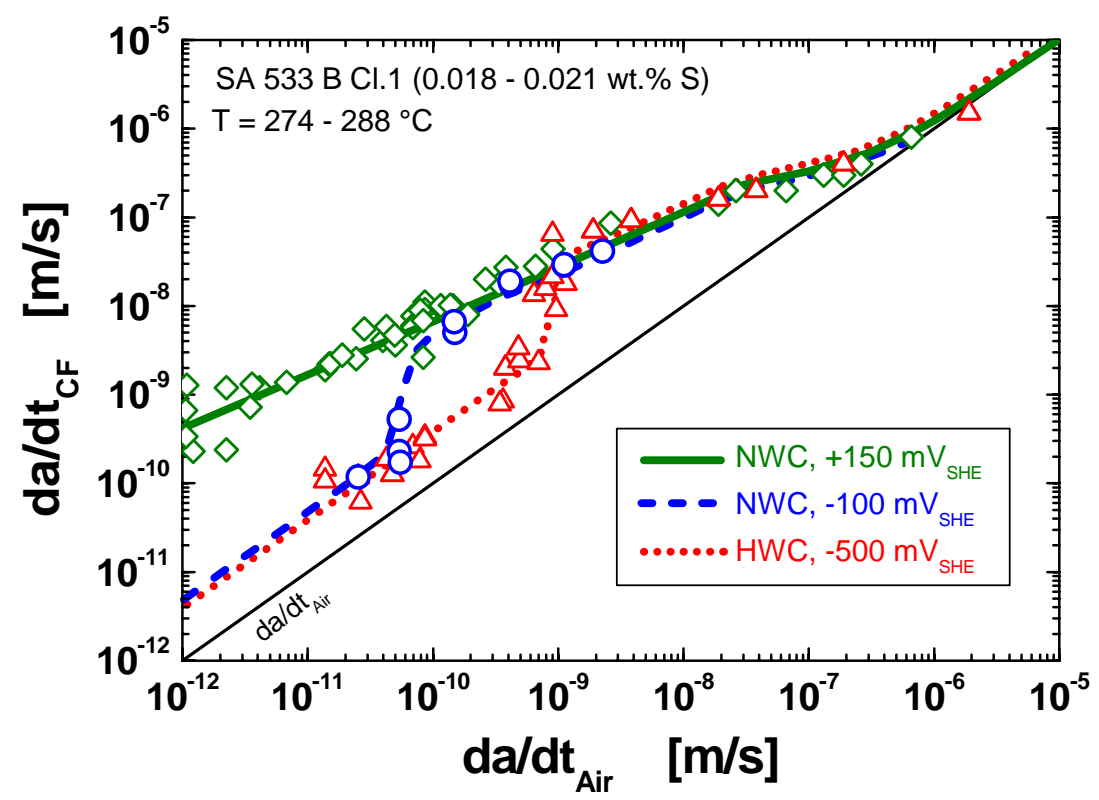

Fig. 5. Effect of ECP/DO content and loading frequency on the time-based CGR da/dt $\mathrm{EAC}_{\text {[C }}$ [13]. 


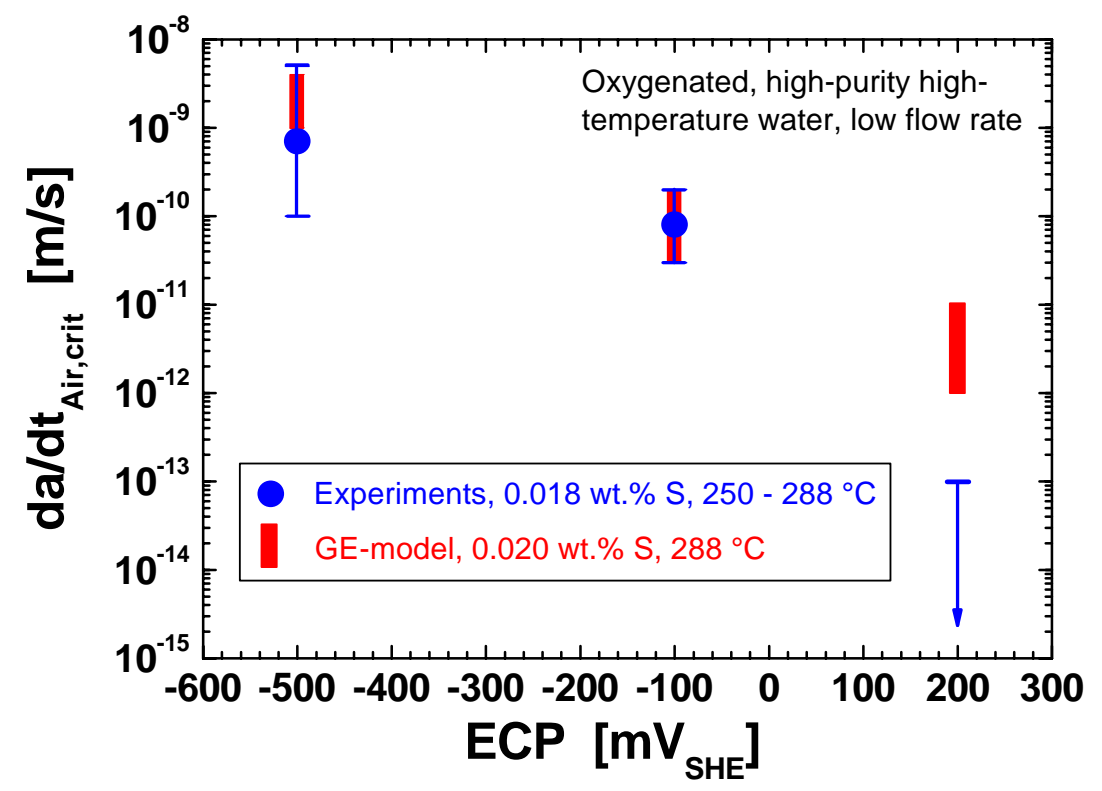

Fig. 6. Comparison between experimentally derived critical air fatigue CGRs da/dt $\mathrm{dir}_{\mathrm{Ai}, \text { rrit }}$ at different ECPs and the predictions of the GE-model. 


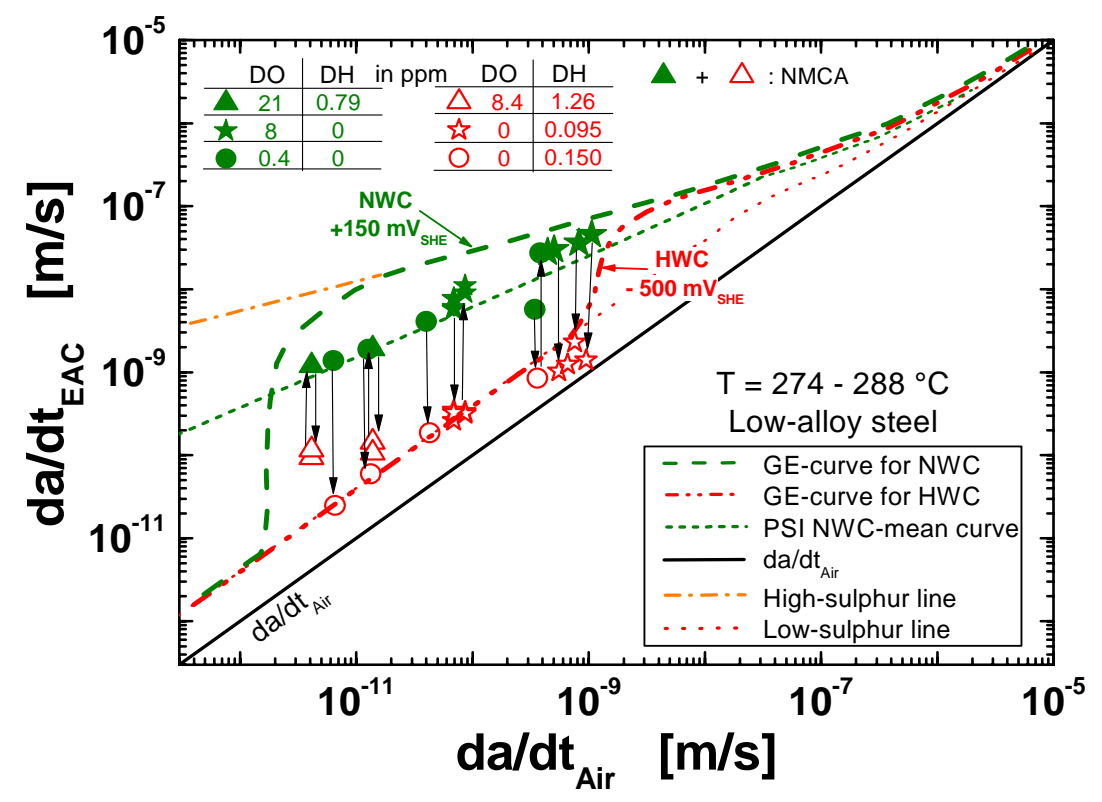

Fig. 7. Time-based CF CGRs under BWR/NWC and HWC/noble metal chemical addition (NMCA) [14] conditions and comparison to the GE-curve for NWC and HWC (DH = dissolved hydrogen content). 


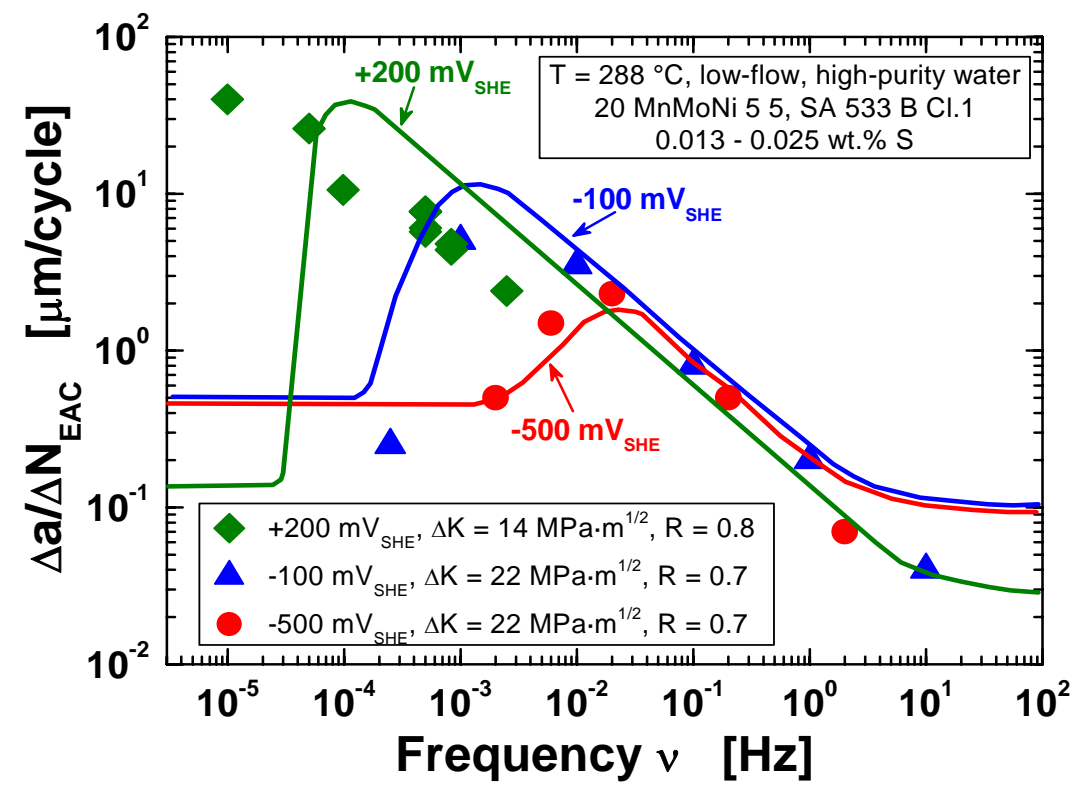

Fig. 8. Comparison of the cycle-based CGR $\Delta \mathrm{a} / \Delta \mathrm{N}_{\mathrm{EAC}}$ at different ECP/DO-levels and frequencies with the predictions of the GE-model. 


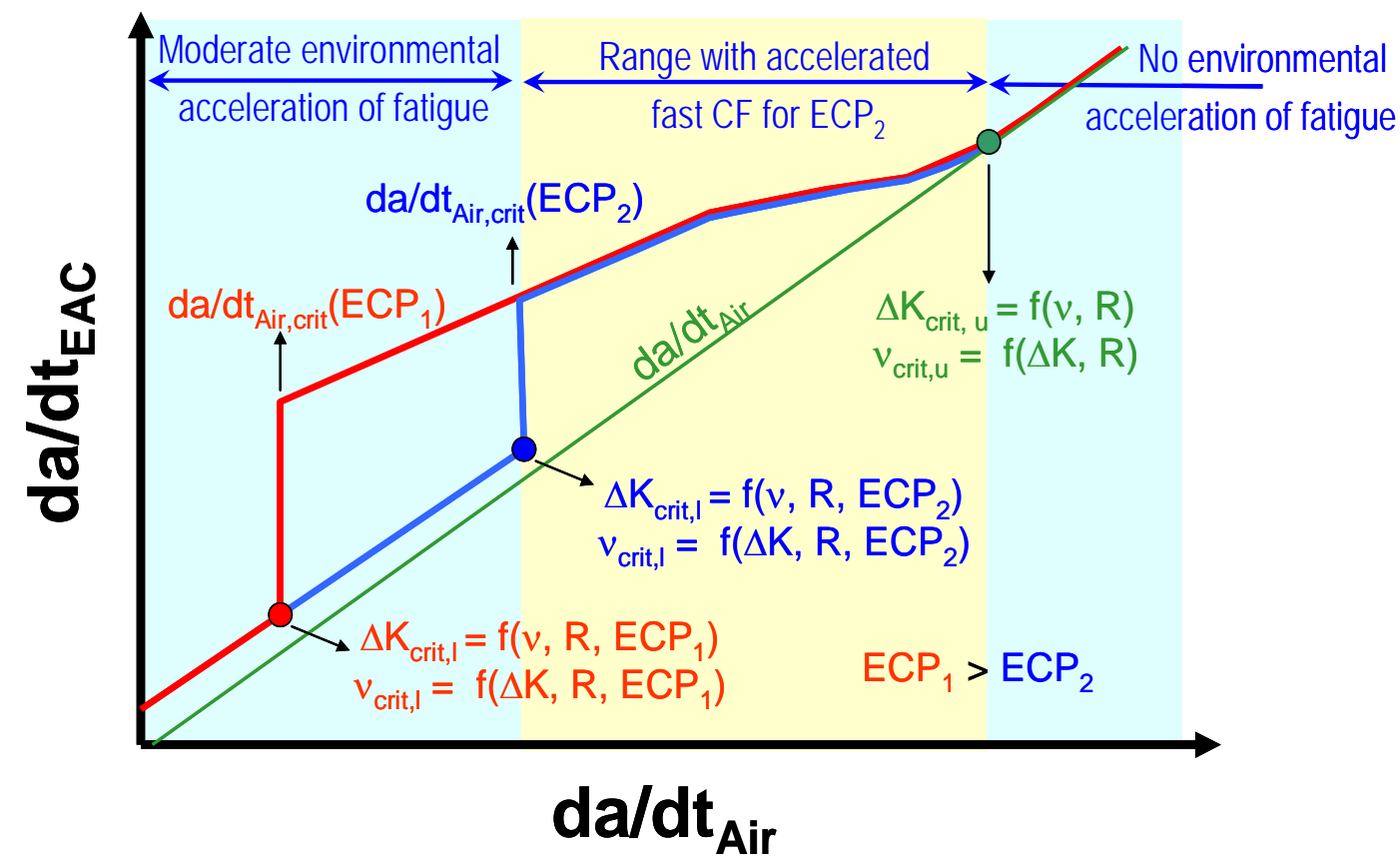

Fig. 9. Schematic of the "time-domain analysis method" and conservative determination of critical air fatigue CGRs da/dt $\mathrm{dt}_{\mathrm{Ai}, \text { crit }}$ for two ECP regimes (steel with high sulphur content/high DSA susceptibility, decreasing loading frequency, and high load ratio $\mathrm{R}(0.5 \leq \mathrm{R} \leq 0.8))$. 


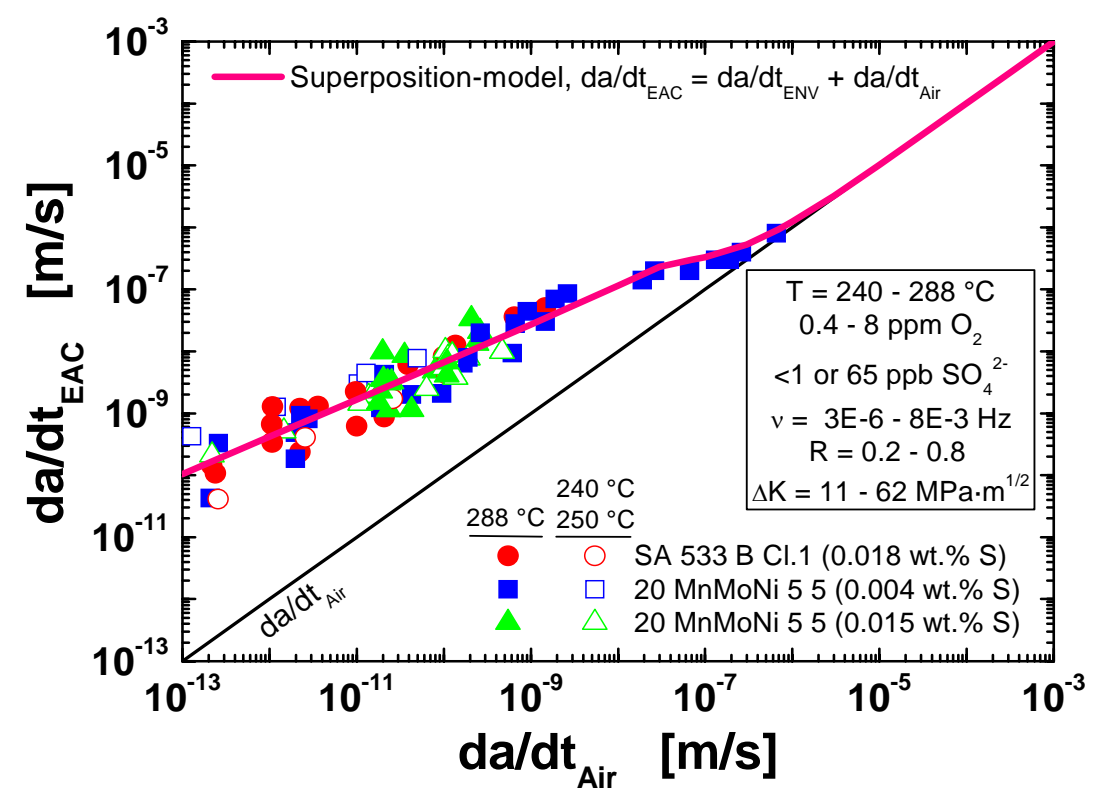

Fig. 10. Time-domain analysis of CF test data in oxygenated high-temperature water with a simple superposition-model. 


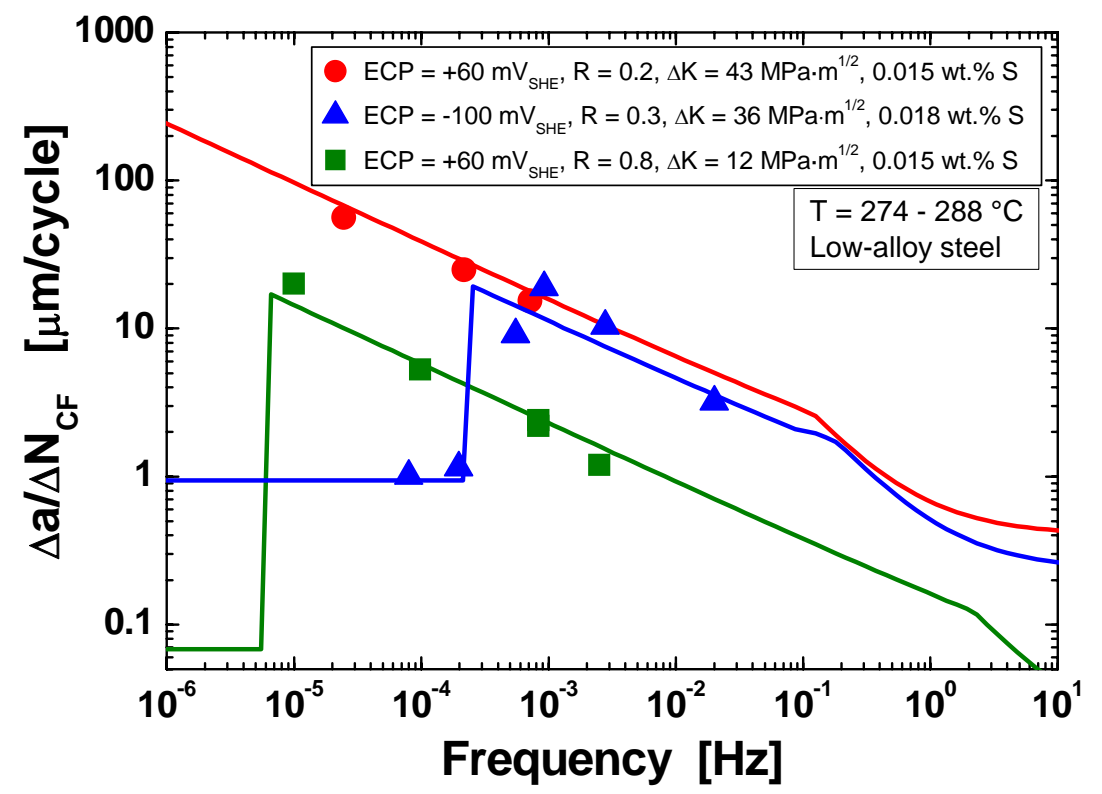

Fig. 11. Reasonable correlation between superposition-model and experimental data at different system conditions [7]. 